\title{
Prevailing Somatotypes and Their Contribution Rate to the Coordination Abilities among the Students of the Physical Education College
}

\author{
Aman Khasawneh \\ Coaching and Sport Management Department, The Hashemite University, Zarqa, Jordan \\ Email: amana752001@yahoo.com
}

Received 20 May 2015; accepted 18 July 2015; published 21 July 2015

Copyright (C) 2015 by author and Scientific Research Publishing Inc.

This work is licensed under the Creative Commons Attribution International License (CC BY). http://creativecommons.org/licenses/by/4.0/ (c) (i) Open Access

\begin{abstract}
This study aimed at identifying the prevailing somatotypes among students according to academic year for males and females, as well as the differences among the frequencies of those prevailing somatotypes. It also aimed at identifying the contribution rates for the somatotype components to the coordinate abilities. A sample of 286 students were chosen, 176 males and 110 females, from the students at the College of Physical Education and Sport Sciences, using stratified random sample method. The results indicated that the Mesomorphic Endomorph somatotype was the prevailing one among males, whereas the Balanced Endomorph somatotype was the prevailing one among females. The results also indicated the existence of differences in the frequencies of somatotypes represented by the prevalence of the Mesomorphic Endomorph somatotype and its difference from the rest somatotypes for both males and females. The study revealed also that the Endomorph somatotype contributed effectively to constant balance and agility among males, whereas the Mesomorph and Ectomorph somatotypes contributed effectively to dynamic balance and agility among females. The researcher recommended the necessity for considering somatotypes when selecting students, who had the Mesomorph somatotype or the Mesomorph and Ectomorph one. He also recommended the necessity of benefiting from this study's results through informing those concerned to have their mechanism and take the required procedures in order to limit the spread of the Endomorph somatotype among students and improve the Mesomorph through certain training programs.
\end{abstract}

\section{Keywords}

Somatotype, Contribution Rate, Coordinates Abilities 


\section{Introduction}

Developing countries seek to build sound communities whose individuals enjoy the ability to encounter the current life requirements, particularly with the spread of hypokinetic diseases. Hence, interest in body-health programs, body safety and suitable weight, and acquiring sound body structure has become an urgent necessity. Also, the interest in caring for movements, the ability of good performance and acquiring the motor and physical fitness has emerged. The big role in implementing these programs belongs to the colleges of physical education and sport sciences, which provide society with specialists in sport activities, who are charged with the responsibility of enforcing this effective vital domain.

One of the vital issues related to what has been mentioned earlier, specially weight and the body's composition and structure, is what is called the somatotype, whose examination is considered as one of the most important topics that researchers should consider. Its importance originated from its relation to many components of motor and physical fitness. In addition, one of the important motives for studying somatotypes is what has been achieved regarding the relationship between the body's structure and its external behavior (Claudio, Daniel, Eunice, Henrique, \& Rita, 2014).

The somatotype technique is the most complete methodology to assess the physical characterization of both body morphology and composition. This technique also allows determining the body morphology and composition associated with a specific health condition, sports or aesthetic issues. Not only does it allow for the individuals to know himself/herself, but it aids to improve his/her physical condition, especially when it is associated to specific sportive activity and/or performance (Claudio et al., 2014).

Anthropometry in general is a systematic technique which sizes the objective characteristics of the human body with principles and classifies the certain methods of measuring according to the structure. In other words, Anthropometry is a perfect evaluation of individual's body features (Tahillioglu, Sevim, Pulur, \& Alpkayu, 2000).

Interest in Anthropometry is incomplete when looking after the shape of the body without considering its abilities. The role of motor fitness appears as one of the physical competence components (Hassanein, 1995), since it enables individuals to do movements effectively, and to perform life requirements and face emergencies effectively. The somatotype is crucial for achieving the best performance of physical requirements that are related to the physical activity, which is positively reflected on the level of motor performance (Allawi, 2005).

Most studies that have addressed somatotypes indicate that the body is composed of three basic compounds known as Ectomorph, Mesomorph, and Endomorph (Arak, 2008; Ibrahim, Hussein, \& Abdal Amir, 2012). Each compound represents a dimension, and these dimensions define the body's external shape which is a quantitative definition of all three components that define the body's external shape. These dimensions were given names and terms: Ectomorph-Thin, Mesomorph-Sportive, and Endomorph-Fat.

These are expressed using three consecutive numbers, where the first one refers to the Endomorph compound, the second number refers to the Mesomorph compound, and the third number refers to the Ectomorph compound. It can also be written in another way, where the left number refers to the Endomorph compound, the middle refers to the Mesomorph, and the right one refers to the Ectomorph compound. The somatotype is usually named in light of the dominant two components.

Somatotypes could be classified into 13 classes on the somatotype card: Central (no component differs by more than one unit from the other two), Balanced Endomorph (Endomorph is dominant and Mesomorphy and Ectomorphy is equal or do not differ by more than one-half unit), Mesomorphic Endomorph (Endomorph is dominant and Mesomorphy is greater than Ectomorphy, Mesomorph-Endomorph (Endomorph and Mesomorphy are equal or do not differ by more than one-half unit), and Ectomorphy is smaller, Endomorphic Mesomorph (Mesomorphy is dominant and Endomorph is greater than Ectomorphy, Balance Mesomorph (Mesomorphy is dominant and Endomorph and Ectomorphy are equal or do not differ by more than one-half unit), Ectomorphic Mesomorph (Mesomorphy is dominant and Ectomorphy is greater than Endomorph), Mesomorph-Ectomorph (Mesomorphy and Ectomorphy are equal or do not differ by more than one-half unit, and Endomorph is smaller). Mesomorphic Ectomorph (Ectomorph is dominant and Mesomorph is greater than Endomorph), Balance Ectomorph (Ectomorph is dominant and Endomorph and Mesomorph are equal or do not differ by more than one-half unit), Endomorphic Ectomorph (Ectomorph is dominant and Endomorph is greater than Mesomorph), Endomorph-Ectomorph (Endomorph and Ectomorph are equal or do not differ by more than one-half unit, and 
Mesomorph is lower), and Ectomorphic Endomorph (Endomorph is dominant and Ectomorph is greater than Mesomorph) (Carter, 2002).

The name is defined depending on the difference of half point, so if the difference is more than half a point, we add (the) to the two dominant compounds. For example, we say the Mesomorph-Ectomorph. If the difference is half a point or less, (the) is deleted, and a hyphen is added between the two components, indicating that there are no differences between the two components. In this case, one compound could precede the other, saying for example, Mesomorph-Ectomorph or Ectomorph-Mesomorph (Allawi, 2005).

The relationship between body structure and physical activity, on which so many various speculations have been done from the ancient times to our days, has been the primary aim of the several studies as it has always been sport scientists' primary concern in terms of reaching conclusions, comparisons and its association with performance (Vedat, 2013).

Sport scientists have intensively studied the athletes' body compositions and physical profiles as well as their physiological profiles (Bilge \& Tuncel, 2003). With the help of the studies on anthropometric characteristics, it has been aimed to determine which different body profiles are appropriate for which sport branches and in the talent identification process the athletes matching those profiles are selected (Sogut, Muniroglu, \& Deliceoglu, 2004).

In order to get a good level of performance in a sport branch, firstly, a suitable body type for that branch is considered to be essential. It is known that the one's inborn body structure has a significant role on physical activity level or on his/her aptness to a specific sport branch, yet there might become some sport specific changes in the physical structure of the body as a result of regular physical activities (Gualdi-russo \& Zacagni, 2001).

Body parts bring up who will be more advantage mechanically during the sports activity as the ratio of the length, wideness and environment. For many years, the appropriate body type has been considered to play an important role in sport performance. The studies reveal significant differences between the body types of the athletes engaged in different sport branches. However, body size, proportion, body composition are important factors that affect physical performance. Anthropometric data is useful because some anthropometric variables are correlated with performance (Van Someren \& Palmer, 2003).

The study of Lundy, O'Connor, Fiona, \& Caterson (2006) pointed out that the prevailing somatotype among professional Rugby players was the Endomorphic Mesomorph one, where attacking players were taller, heavier and fatter compared with the defending players.

On the other hand, the study of Liiv et al. (2013) indicated that the anthropometric measurements play a significant role in the domain of dancing and aesthetic sports during the selection process and achievement criteria. The findings revealed that the participants' somatotypes differ in the dancing sport depending on dancing types, and that the male and female dancers have less ratio of Mesomorph compound and more ratio of Ectomorph compound. However, Allawi (2005) referred to the deficiency in the Mesomorph compound within all activities like jumping and running, met with a relative increase in the Ectomorph compound. However, Al-Thaher (2013) said that the Balanced Mesomorph somatotype is the prevailing one among the students of teacher-preparation institutions, whereas the study's findings of Muhammed, Nasir, Yousef, \& Muhammed (2009), conducted on school students, indicated that the Mesomorphic Endomorph somatotype is the dominant among males, and the Mesomorphic Ectomorph somatotype is the prevailing one among females.

Hussein (2004) found that the Mesomorph compound is the least somatotype being exposed to knee ligament injury, whereas the most exposed one is the Ectomorph somatotype then the Endomorph. Also, Ibrahim \& Others (2012) found that the prevailing somatotype among the female students of the physical education college is the Endomorph.

So, it is extremely important to study body structure and athletes' achievement limitations in different sports because improving physical activity requires high-level physical abilities such as endurance, strength and speed. On the other hand, performance tests, including physical ones and anthropometric measurements, play a major role in defining these abilities (Colakoglu, Er, Ipekoglu, Karacan, Colakoglu, \& Zorba, 2014).

Defining the somatotype offers us a measuring tool that could be accredited when judging the bodies' validity, enabling us to try improving and modifying. Also, taking care of the body structure represented by uncovering its somatotypes and coordinate abilities can't be done independently because human's abilities interrelate and affect each other. Here emerges the importance of this attempt for discovering the prevailing somatotypes among students, and their contribution rate and impact on the coordinate abilities in order to enforce them for 
the purpose of achieving ideal levels for students.

\subsection{The Problem of the Study}

The profession of physical education requires specific qualifications and basic requirements for those who want to work in this field, so the main factor for good selection is the student's own character represented in its psychological and physical components. Since the process of selecting students in the college of physical education is considered a significant foundation upon which the most appropriate applicants are chosen to complete the studying programs, it is necessary to apply ongoing objective assessment for all applicants' characteristics applying for the college of physical education.

The researcher noticed that there is a difference and variance in the male and female students' body structure because of stopping work on the acceptance tests, and there is a clear variance in the motor, physical and coordinate levels, and consequently that affects students' achievement level and increases the teachers' burden and efforts in an attempt to have students acquire a good level of skills and fitness. It also affects the graduates' level when being engaged in practical life that requires competence and ability to prove one's self. Hence, the researcher decided to conduct such a study in order to identify the prevailing somatotypes and their frequencies among the college students, and their contribution to some coordinate abilities so that they could be examined and logical solutions could be found for the purpose of raising students' general level.

\subsection{Objectives}

The study aimed to identify the prevailing somatotypes among students of Physical Education College according academic year for both males and females, also to Identify the differences between observed and expected frequencies of somatotypes' among male and female students, moreover to determine the contribution percentages of the somatotype components to the coordination abilities among male and female students.

\section{Methodology}

The researcher used the descriptive approach, with the pattern of surveys and correlation studies, given its appropriateness for the nature of the study.

\subsection{Population and Sample}

The sample was taken from the students of the physical education college during the university year 2015/2016, including males and females enrolled in the department of Sport Management and Training, with a total of (286). 172 were male students, whereas 110 were females, representing a percentage of $(68.42 \%)$ from the study population. stratified random sample from different academic years were used in selecting the sample. Table 1 clarifies the sample description.

\subsection{Instruments}

Tests and measures were used as instruments for gathering data from the sample of the study, where the re-

Table 1. Description of the study sample.

\begin{tabular}{ccccccc}
\hline \multirow{2}{*}{ Stage } & \multicolumn{3}{c}{ Males } & \multicolumn{2}{c}{ Females } & \multicolumn{2}{c}{ Total } \\
\cline { 2 - 7 } & Number & Percentage & Number & Percentage & Number & Percentage \\
\hline 1st year & 44 & $15.38 \%$ & 27 & $9.44 \%$ & 71 & $24.83 \%$ \\
2nd year & 44 & $15.38 \%$ & 28 & $9.79 \%$ & 72 & $25.17 \%$ \\
3rd year & 44 & $15.38 \%$ & 28 & $9.79 \%$ & 72 & $25.17 \%$ \\
4th year & 44 & $15.38 \%$ & 27 & $9.44 \%$ & 71 & $24.38 \%$ \\
Total & 176 & $61.54 \%$ & 110 & $38.46 \%$ & 286 & $100 \%$ \\
\hline
\end{tabular}


searcher used the following tools:

1) Heath \& Carter Anthropometric method for identifying the sample's somatotype;

2) Test Battery of motor fitness used in the students' test by the Physical Education College, containing the following components;

3) Test of standing on foot on the Balance beam using the longitudinal method for measuring the static balance;

4) Test of walking on the Octagon device for measuring the dynamic balance;

5) Numbered circles' test for measuring coordination;

6) Running around cones for measuring agility.

\subsubsection{Tools and Equipment}

The tool for measuring height, a medical scale for measuring weight, a metric tape measure for circumferences, a pelvimeter for measuring widths, a Skin Fold Caliper for measuring fat thickness, the Balance Beam for measuring static balance, the Octagon device for measuring dynamic balance, cones, electronic stop watches, a whistle, crayons and chalks, a compass for drawing circles on the ground, and results registering form.

The Heath-Carter Somatotype Rating Form: (Carter, 2002)

1) Record pertinent identification data in top section of rating form.

Endomorphy rating (steps 2 - 5)

2) Record the measurements for each of the four skin folds.

3) Sum the triceps, sub scapular, and supraspinale skin folds; record the sum in the box opposite SUM3 SKINFOLDS. Correct for height by multiplying this sum by (170.18/height in $\mathrm{cm})$.

4) Circle the closest value in the SUM3 SKINFOLDS table to the right. The table is read vertically from low to high in columns and horizontally from left to right in rows. "Lower limit" and "upper limit" on the rows provide exact boundaries for each column. These values are circled only when SUM3 SKINFOLDS are within 1 $\mathrm{mm}$ of the limit. In most cases circle the value in the row "midpoint".

5) In the row for endomorphy circle the value directly under the column for the value circled in number (4) above.

Mesomorphy rating (steps 6 - 10)

6) Record height and breadths of humerus and femur in the appropriate boxes. Make the corrections for skin folds before recording girths of biceps and calf (skinfold correction: Convert triceps skinfold to $\mathrm{cm}$ by dividing by 10. Subtract converted triceps skinfold from the biceps girth. Convert calf skinfold to cm, subtract from calf girth).

7) In the height row directly to the right of the recorded value, circle the height value nearest to the measured height of the subject (note: Regard the height row as a continuous scale).

8) For each bone breadth and girth circle the number nearest the measured value in the appropriate row (note: Circle the lower value if the measurement falls midway between two values. This conservative procedure is used because the largest girths and breadths are recorded).

9) Deal only with columns, not numerical values for the two procedures below. Find the average deviation of the circled values for breadths and girths from the circled value in the height column as follows:

a) Column deviations to the right of the height column are positive deviations. Deviations to the left are negative deviations (circled values directly under the height column have deviations of zero are ignored).

b) Calculate the algebraic sum of the \pm deviations (D). Use this formula: Mesomorphy $=(D / 8)+4.0$. Round the obtained value of Mesomorphy to the nearest one-half (1/2) rating unit.

10) In the row for mesomorphy circle the closest value for Mesomorphy obtained in number 9 above. (If the point is exactly midway between two rating points, circle the value closest to 4 in the row. This conservative regression toward 4 guards against spuriously extreme ratings).

Ectomorphy rating (steps $11-14$ )

11) Record weight (kg).

12) Obtain height divided by cube root of weight (HWR). Record HWR in the appropriate box.

13) Circle the closest value in the HWR table to the right (see note in number (4) above).

14) In the row for Ectomorphy circle the Ectomorphy value directly below the circled HWR.

15) Move to the bottom section of the rating form. In the row for Anthropometric Somatotype, record the circled ratings for Endomorphy, Mesomorphy and Ectomorphy. 
16) Sign your name to the right of the recorded rating.

The identification data in the upper section of the rating form are somewhat arbitrary.

Investigators may change these to suit their purposes.

\subsubsection{Defining the Components of Coordination Abilities}

For defining the components of coordination abilities, a group of experts and specialists were interviewed, and then they agreed upon the following components which conducted from the survey of previous studies:

(Static balance, dynamic balance, agility, and coordination)

\subsubsection{Defining the Tests}

After defining the coordination abilities, tests which measure these abilities were identified. Also, they used the test-battery for motor and physical abilities which is used for testing the physical education college students, and it was reviewed by experts to identify its suitability for achieving the targeted goal and its validity.

\subsubsection{Reliability}

The tests were conducted on a sample containing ten participants (college students) included in the study population on the 1st of March, 2015 so as to implement the first application. They were also re-applied on the same sample on the 8th of March, 2015 so as to find out reliability using test-retest method. The tests achieved reliability coefficients that are statistically significant, where the correlation value of the static balance test reached (0.99), the dynamic balance test (0.93), agility test (0.96), and coordination test reached (0.97), and all of them scored a significance level of $(P=0.001)$.

\subsubsection{The Pilot Study}

The researcher conducted a pilot study on the 15th of March, 2015 on a sample containing ten college students to ensure assistant teams competency in implementing tests and measurements and recording scores, where instructions were offered regarding the way they would measure the anthropometric variables relevant to somatotype. The result of this experiment showed that the time needed for conducting measurements so as to identify the somatotype ranged from (4-5) minutes as well as for the coordinating abilities, noting that the researcher didn't start the final experiment unless he ensured the assistants' competency and the validity of devices used , in addition to identifying the difficulties he may face.

\subsubsection{The Main Experiment}

The main experiment was conducted during the period (22-26/3/2015), where they started conducting anthropometric measurements first, following the given sequence: (height, weight, fat thickness, widths, circumferences). Then, they conducted the tests of coordinating abilities, where they allocated the morning period for doing the body measurements (from 8 to 12), and the second period was for the coordinating tests.

\subsection{Data analysis}

1) Means and standard deviations were used to achieve the first objective;

2) Chi-square for observed and expected frequencies for the prevailing somatotypes were used to achieve the second objective;

3) Stepwise regression method to identify the contribution percentage of somatotypes to the coordinating abilities in order to achieve the third objective.

\section{Results}

For achieving the first objective, which refers to identify the prevailing somatotypes among the students according to academic year for both males and females, means and standard deviations were used, as clarified in Table 2 and Table 3.

It is clear in the table the prevailing somatotype among the male students sample in general (for all academic years) is the Mesomorphic endomorph as well as for the 3rd and 4th academic years, whereas the Balanced endomorph appeared among the 1 st and 2 nd academic years. This indicated that the endomorph somatotype is the 
Table 2. Descriptive statistics of prevailing somatotypes among male students according to the academic year.

\begin{tabular}{|c|c|c|c|c|c|c|}
\hline \multirow{2}{*}{ Academic Year } & \multirow{2}{*}{$\mathrm{N}$} & \multirow{2}{*}{ Statistic } & \multicolumn{3}{|c|}{ Somatotype Categories } & \multirow{2}{*}{ Common Somatotype } \\
\hline & & & Endomorph & Mesomorph & Ectomorph & \\
\hline \multirow{2}{*}{ First } & \multirow{2}{*}{44} & Mean & 4.2955 & 2.6364 & 2.8409 & \multirow{2}{*}{ Balanced Endomorph } \\
\hline & & Std. Deviation & 1.57863 & .99044 & 1.07710 & \\
\hline \multirow{2}{*}{ Second } & \multirow{2}{*}{44} & Mean & 4.8140 & 2.8605 & 2.7674 & \multirow{2}{*}{ Balanced Endomorph } \\
\hline & & Std. Deviation & 1.38454 & 1.31984 & 1.47740 & \\
\hline \multirow{2}{*}{ Third } & \multirow{2}{*}{44} & Mean & 4.2045 & 3.3182 & 2.7955 & \multirow{2}{*}{ Mesomorphic Endomorph } \\
\hline & & Std. Deviation & 1.54889 & 1.53672 & 1.39066 & \\
\hline \multirow{2}{*}{ Forth } & \multirow{2}{*}{44} & Mean & 4.3182 & 3.5909 & 2.3864 & \multirow{2}{*}{ Mesomorphic Endomorph } \\
\hline & & Std. Deviation & 1.73571 & 1.64696 & 1.35055 & \\
\hline \multirow{2}{*}{ Total } & \multirow{2}{*}{176} & Mean & 4.4057 & 3.1029 & 2.6971 & \multirow{2}{*}{ Mesomorphic Endomorph } \\
\hline & & Std. Deviation & 1.57238 & 1.43469 & 1.33250 & \\
\hline
\end{tabular}

Table 3. Descriptive statistics of prevailing somatotypes among female students according to the academic year.

\begin{tabular}{|c|c|c|c|c|c|c|}
\hline \multirow{2}{*}{ Academic Year } & \multirow{2}{*}{$\mathrm{N}$} & \multirow{2}{*}{ Statistic } & \multicolumn{3}{|c|}{ Somatotype Categories } & \multirow{2}{*}{ Common Somatotype } \\
\hline & & & Endomorph & Mesomorph & Ectomorph & \\
\hline \multirow{3}{*}{ First } & \multirow{3}{*}{27} & Mean & 6.0370 & 2.6667 & 1.8148 & \multirow{3}{*}{ Mesomorphic Endomorph } \\
\hline & & & & & & \\
\hline & & Std. Deviation & 1.48016 & 1.10940 & 0.83376 & \\
\hline \multirow{3}{*}{ Second } & \multirow{3}{*}{28} & Mean & 5.6429 & 2.2500 & 2.1786 & \multirow{3}{*}{ Balance Endomorph } \\
\hline & & & & & & \\
\hline & & Std. Deviation & 1.61507 & .92796 & 1.12393 & \\
\hline \multirow[b]{2}{*}{ Third } & \multirow[b]{2}{*}{28} & Mean & 5.3214 & 2.2857 & 2.3214 & \multirow[b]{2}{*}{ Balance Endomorph } \\
\hline & & Std. Deviation & 1.61138 & 1.01314 & 1.46701 & \\
\hline \multirow{3}{*}{ Forth } & \multirow{3}{*}{26} & Mean & 5.3077 & 3.0385 & 2.0385 & \multirow{3}{*}{ Mesomorphic Endomorph } \\
\hline & & & & & & \\
\hline & & Std. Deviation & 1.97523 & 1.77721 & 1.18257 & \\
\hline \multirow{3}{*}{ Total } & \multirow{3}{*}{110} & Mean & 5.5780 & 2.5505 & 2.0917 & \multirow{3}{*}{ Balance Endomorph } \\
\hline & & & & & & \\
\hline & & Std. Deviation & 1.67936 & 1.26554 & 1.17490 & \\
\hline
\end{tabular}

dominant component among other components (Mesomorph and Ectomorph), indicating the weak practical aspect that helps improve student's physical and muscular aspects.

It is clear in the table the prevailing somatotype among the female students sample in general (for all academic years) is the Balanced endomorph as well as for the 2nd and 3rd academic years, whereas the Mesomorphic endomorph appeared among the 1st and 4th academic years. This indicated that the endomorph somatotype is the dominant component among other components (Mesomorph and Ectomorph), indicating the weak muscular aspect among girls.

For achieving the second object, which refers to identifying the differences between observed and expected frequencies, for prevailing somatotypes among male and female students, chi-square test was used as clarified in Table 4 and Table 5.

The prevailing somatotypes among the male sample were distributed in 10 types according to the sample results, and the Mesomorphic endomorph one came first with a frequency of (60), whereas the Ectomorphic Endomorph came second with a frequency of (27), followed by the Endomorphic Mesomorph (24), and the Endo 
Table 4. Chi-square results for prevailing somatotypes among male students.

\begin{tabular}{|c|c|c|c|c|c|c|c|c|c|c|}
\hline Symototype/Freq & Observed N & $\begin{array}{c}\text { Expected } \\
\mathrm{N}\end{array}$ & $\begin{array}{c}\text { Observed } \\
\mathrm{N}\end{array}$ & $\begin{array}{c}\text { Expected } \\
\mathrm{N}\end{array}$ & $\begin{array}{c}\text { Observed } \\
\mathrm{N}\end{array}$ & $\begin{array}{c}\text { Expected } \\
\mathrm{N}\end{array}$ & $\begin{array}{c}\text { Observed } \\
\mathrm{N}\end{array}$ & $\begin{array}{c}\text { Expected } \\
\mathrm{N}\end{array}$ & $\begin{array}{c}\text { Observed } \\
\mathrm{N}\end{array}$ & $\begin{array}{c}\text { Expected } \\
\mathrm{N}\end{array}$ \\
\hline $\begin{array}{l}\text { Mesomorphic } \\
\text { Endomorph }\end{array}$ & 19 & 4.9 & 14 & 4.9 & 13 & 4.9 & 14 & 4.9 & 60 & 17.6 \\
\hline Endomorphic Ectomorph & 6 & 4.9 & 7 & 4.9 & 5 & 4.9 & 5 & 4.9 & 23 & 17.6 \\
\hline Ectomorphic Endomorph & 7 & 4.9 & 7 & 4.9 & 8 & 4.9 & 5 & 4.9 & 27 & 17.6 \\
\hline Balance Endomorph & 3 & 4.9 & 7 & 4.9 & 4 & 4.9 & 1 & 4.9 & 15 & 17.6 \\
\hline Central & 1 & 4.9 & - & 4.9 & - & 4.9 & 1 & 4.9 & 2 & 17.6 \\
\hline Balance Mesomorph & 2 & 4.9 & 2 & 4.9 & 4 & 4.9 & 1 & 4.9 & 9 & 17.6 \\
\hline Endomorphic Mesomorph & 2 & 4.9 & 3 & 4.9 & 6 & 4.9 & 13 & 4.9 & 24 & 17.6 \\
\hline Ectomorphic Mesomorph & 3 & 4.9 & 1 & 4.9 & 1 & 4.9 & 1 & 4.9 & 6 & 17.6 \\
\hline Balance Ectomorph & 1 & 4.9 & 2 & 4.9 & 1 & 4.9 & 3 & 4.9 & 7 & 17.6 \\
\hline $\begin{array}{l}\text { Mesomorphic } \\
\text { Ectomorph }\end{array}$ & - & 4.9 & 1 & 4.9 & 2 & 4.9 & - & 4.9 & 3 & 17.6 \\
\hline Chi-Square & \multicolumn{2}{|c|}{52.955} & \multicolumn{2}{|c|}{30.045} & \multicolumn{2}{|c|}{23.909} & \multicolumn{2}{|c|}{43.545} & \multicolumn{2}{|c|}{157.864} \\
\hline Asymp. Sig. & \multicolumn{2}{|c|}{0.001} & \multicolumn{2}{|c|}{0.001} & \multicolumn{2}{|c|}{0.002} & \multicolumn{2}{|c|}{0.001} & \multicolumn{2}{|c|}{0.001} \\
\hline
\end{tabular}

Table 5. Chi-square results for prevailing somatotypes among female students.

\begin{tabular}{|c|c|c|c|c|c|c|c|c|c|c|}
\hline \multirow[b]{2}{*}{ Symototype/Freq } & \multicolumn{2}{|c|}{ First } & \multicolumn{2}{|c|}{ Second } & \multicolumn{2}{|c|}{ Third } & \multicolumn{2}{|c|}{ Fourth } & \multicolumn{2}{|c|}{ Total } \\
\hline & $\begin{array}{c}\text { Observed } \\
\mathrm{N}\end{array}$ & $\begin{array}{c}\text { Expected } \\
\mathrm{N}\end{array}$ & Observed N & $\begin{array}{c}\text { Expected } \\
\mathrm{N}\end{array}$ & Observed N & $\begin{array}{c}\text { Expected } \\
\mathrm{N}\end{array}$ & Observed N & $\begin{array}{c}\text { Expected } \\
\mathrm{N}\end{array}$ & $\begin{array}{c}\text { Observed } \\
\mathrm{N}\end{array}$ & $\begin{array}{c}\text { Expected } \\
\mathrm{N}\end{array}$ \\
\hline $\begin{array}{l}\text { Mesomorphic } \\
\text { Endomorph }\end{array}$ & 17 & 5.4 & 11 & 5.6 & 13 & 4.7 & 11 & 3.9 & 52 & 13.8 \\
\hline $\begin{array}{l}\text { Endomorphic } \\
\text { Ectomorph }\end{array}$ & 0 & 5.4 & 1 & 5.6 & 4 & 4.7 & 2 & 3.9 & 7 & 13.8 \\
\hline $\begin{array}{l}\text { Ectomorphic } \\
\text { Endomorph }\end{array}$ & 5 & 5.4 & 6 & 5.6 & 4 & 4.7 & 3 & 3.9 & 18 & 13.8 \\
\hline Balanced Endomorph & 2 & 5.4 & 6 & 5.6 & 4 & 4.7 & 7 & 3.9 & 19 & 13.8 \\
\hline Central & 2 & 5.4 & 4 & 5.6 & 2 & 4.7 & 2 & 3.9 & 10 & 13.8 \\
\hline Balance Mesomorph & 0 & 5.4 & 0 & 5.6 & 0 & 4.7 & 1 & 3.9 & 1 & 13.8 \\
\hline $\begin{array}{l}\text { Endomorphic } \\
\text { Mesomorph }\end{array}$ & 0 & 5.4 & 0 & 5.6 & 0 & 4.7 & 1 & 3.9 & 1 & 13.8 \\
\hline $\begin{array}{l}\text { Ectomorphic } \\
\text { Mesomorph }\end{array}$ & 1 & 5.4 & 0 & 5.6 & 1 & 4.7 & 0 & 3.9 & 2 & 13.8 \\
\hline Chi-Square & \multicolumn{2}{|c|}{9.50} & \multicolumn{2}{|c|}{32.815} & \multicolumn{2}{|c|}{19.571} & \multicolumn{2}{|c|}{22} & \multicolumn{2}{|c|}{147.745} \\
\hline Asymp. Sig. & \multicolumn{2}{|c|}{0.045} & \multicolumn{2}{|c|}{0.001} & \multicolumn{2}{|c|}{0.002} & \multicolumn{2}{|c|}{0.001} & \multicolumn{2}{|c|}{0.001} \\
\hline
\end{tabular}

morphic Ectomorph (23), regarding the entire total of the sample as well as the four academic levels. When calculating the chi-square value for the observed frequencies and comparing them with the expected values, it was (157.864) with a significance level of $(P=0.001)$, which refers to the significant differences in the sample regarding the somatotypes.

Thus, it is clear that the prevailing somatotype among the physical education college male students is the Endomorphic one, then the other two types, Ectomorphic and Mesomorphic, alternately appeared with the existence of the Endomorphic component regarding the (2nd, 3rd, and 4th) somatotypes, while the Ectomorphic and Mesomorphic ones were equal. That ascertains the prevalence of Endomorphic component among the males, 
which is contrary to what was expected, because it was expected that the prevailing somatotype is going to be the Mesomorphic. That's ascribed to the clear weakness in focusing on practical courses since it has been noticed in the last five years the increase in the number of students enrolled in the practical sections as a result of the increase in the number of students enrolled in the college, offering less opportunities for skill-training, in addition to the weak fitness level among students. Also, most of the students are non-athletes, and their bodies are obese and overweight.

This contradicts what (Al-Thaher's, 2013) study indicated in that the prevailing somatotype among the students of teachers' institution was the Balanced Mesomorph one. It also differs from Al-Salaimeh's (1994) study which said that the prevailing somatotype among the students of Physical Education College was the Mesomorph one, because it was Ectomorphic Mesomorph for the 1st and 3rd year students and Endomorphic Mesomorph for the 2nd and 4th year students.

It also contradicts with the study of (Lundy et al., 2006), which indicated that the Ectomorphic Mesomorph is the prevailing somatotype among the rugby players, and the study of (Liiv et al., 2013) which pointed out the prevailing one is the Ectomorph among the rhythmic dancers. It agrees with the study of (Muhammed et al., 2009) which said that the dominant somatotype among males is the Mesomorphic Endomorph.

The prevailing somatotypes among the female sample were distributed in 8 types according to the sample results, and the Mesomorphic Endomorph one came first with a frequency of (52), whereas the Balanced Endomorph came second with a frequency of (19), followed by the Endomorphic Ectomorph (18), regarding the entire total of the sample as well as the four academic levels. When calculating the chi-square value for the observed frequencies and comparing them with the expected values, it was (147.745) with a significance level of $(P=0.001)$, which refers to the significant differences in the sample regarding the somatotypes.

Thus, it is clear that the prevailing somatotype among the physical education college female students is the Endomorphic one, and then the other 2 types, Mesomorphic and Ectomorph, alternately appeared with the existence of the Endomorphic component regarding these somatotypes, while the Ectomorphic and Mesomorphic ones were equal. That ascertains the prevalence of Endomorphic component among the females, which is similar to what was expected, because it was expected that the prevailing somatotype is going to be the Endomorphic somatotype. That's ascribed to the fact that the majority of female students didn't want to have this specialty, most of them are non-athletes, and they have weak efficiency for participating in physical tasks and activities inside and outside lectures, in addition to their negative attitude and shyness towards participating effectively in mutual practical lectures with males, particularly within the courses of physical preparation and fitness. This may also be ascribed to the same reason mentioned before in the context of males. This result agrees with the results of (Ibrahim's et al., 2012) study which pointed out that the prevailing somatotype among the female students of Physical Education College is the Endomorphic. It contradicts with the study of (Muhammed et al., 2009) which indicated that the Ectomorphic is the prevailing one among the female students, and the study of (Liiv et al., 2013) that said the Ectomorphic somatotype is the prevailing one among the rhythmic dancers.

For achieving the third objective, which refers to identifying the contribution percentages of somatotype components to the coordinating abilities among male and female students, stepwise regression analysis was used as shown in Table 6 and Table 7.

Table 6. Results of stepwise regression analysis for contribution percentage of somatotype components in coordinating abilities among males.

\begin{tabular}{|c|c|c|c|c|c|c|c|c|c|c|}
\hline Coordination Ability & $\mathrm{R}$ & R Square & $\begin{array}{c}\text { Adjusted R } \\
\text { Square }\end{array}$ & $\begin{array}{l}\text { R Square } \\
\text { Change }\end{array}$ & $\mathrm{F}$ & Sig. & & Model & Beta & Sig. \\
\hline \multirow[b]{2}{*}{ Static Balance } & \multirow[b]{2}{*}{$0.202^{\mathrm{a}}$} & \multirow[b]{2}{*}{0.041} & \multirow[b]{2}{*}{0.035} & \multirow[b]{2}{*}{0.041} & \multirow[b]{2}{*}{70.387} & \multirow[b]{2}{*}{$0.007^{\mathrm{a}}$} & \multirow[b]{2}{*}{1} & (Constant) & & 0.001 \\
\hline & & & & & & & & Endomorph & -0.202 & 0.007 \\
\hline Dynamic Balance & $0.108^{\mathrm{a}}$ & 0.012 & -0.006 & 0.012 & 0.675 & $0.568^{\mathrm{a}}$ & 1 & (Constant) & & 0.001 \\
\hline \multirow{2}{*}{ Agility } & \multirow{2}{*}{$0.165^{\mathrm{a}}$} & \multirow{2}{*}{0.027} & \multirow{2}{*}{0.021} & \multirow{2}{*}{0.027} & \multirow{2}{*}{40.814} & \multirow{2}{*}{$0.030^{\mathrm{a}}$} & \multirow{2}{*}{1} & (Constant) & & 0.001 \\
\hline & & & & & & & & Endomorph & 0.165 & 0.030 \\
\hline Coordination & $0.135^{\mathrm{a}}$ & 0.018 & 0.001 & 0.018 & 10.062 & $0.367^{\mathrm{a}}$ & 1 & (Constant) & 7.563 & 0.001 \\
\hline
\end{tabular}


Table 7. Results of stepwise regression analysis for contribution percentage of somatotype components in coordinating abilities among females.

\begin{tabular}{|c|c|c|c|c|c|c|c|c|c|c|}
\hline Coordination Ability & $\mathrm{R}$ & R Square & $\begin{array}{c}\text { Adjusted R } \\
\text { Square }\end{array}$ & $\begin{array}{l}\text { R Square } \\
\text { Change }\end{array}$ & $\mathrm{F}$ & Sig. & & Model & Beta & Sig. \\
\hline \multirow[t]{2}{*}{ Static Balance } & $0.226 \mathrm{a}$ & 0.051 & 0.024 & 0.051 & 10.880 & $0.137 \mathrm{a}$ & 1 & (Constant) & & 0.001 \\
\hline & & & & 0.141 & & & & (Constant) & & 0.001 \\
\hline \multirow[t]{3}{*}{ dynamic Balance } & $0.375 b$ & 0.141 & 0.124 & 0.102 & 80.669 & $0.000 \mathrm{~b}$ & 2 & Mesomorph & 0.385 & 0.001 \\
\hline & & & & 0.038 & & & & Ectomorph & 0.206 & 0.032 \\
\hline & & & & 0.092 & & & & (Constant) & & 0.001 \\
\hline \multirow[t]{2}{*}{ Agility } & $0.303 b$ & 0.092 & 0.075 & 0.054 & 50.376 & $0.006 \mathrm{~b}$ & 2 & Mesomorph & 0.297 & 0.003 \\
\hline & & & & 0.038 & & & & Ectomorph & 0.207 & 0.036 \\
\hline Coordination & $0.118 \mathrm{a}$ & 0.014 & -0.014 & 0.014 & 0.497 & $0.685 a$ & 1 & (Constant) & & 0.001 \\
\hline
\end{tabular}

It is clear in the table that the only somatotype which contributed effectively to the coordinating abilities is the Endomorphic component for the variable of static balance, which has a statistically significant contribution. Itspartial contribution level (R Square Change) was 0.041 , which is a statistically significant percentage because the corresponding significant level for its standard value was $(P=0.001)$. Also, the only somatotype which contributed effectively to the variable of agility was the Endomorphic component which has a statistically significant contribution that reached (0.027), a statistically significant level because its corresponding significant level for its standard value was $(P=0.001)$. On the other hand, there were no influences or relations for the other somatotypes on the variables of dynamic balance and coordination.

We can see that these results are acceptable because there is a negative relation between the Endomorphic somatotype and static balance since the standard value of their relationship was negative, which means the more the Endomorphic somatotype increases, the individual's ability to maintain static balance decreases. It is known that the static balance requires the individual's ability to maintain balance for as long as possible, and that needs a muscular power as well as muscular endurance for the muscles of legs and trunk so as to be able to perform that task. That what the individual who has the Endomorphic somatotype usually lacks. Also, overweight because of obesity affects the muscles' ability of contraction. This result contradicts what (Al-Thaher, 2013) said in that there is no relationship between the Endomorphic somatotype and static balance.

As noted in the table, there is a positive correlation between the Endomorphic somatotype and agility, and this is a logical result since agility requires the individual's ability to change directions in the least time possible, in which the individual's muscular level and strength needed for these tests play a large role. Thus, the least time is the best, and the existence of a positive correlation means that the more the Endomorphic component increases, the more the agility time increases, and vice versa. That is ascribed to the fact that the Endomorphic component is distinguished by little growth of bones and muscles, and that affects the motor system and weakens movement and achievement, besides that the endomorphic somatotype usually has the accumulation of fat. This result agrees with what (Hassanein, 2003) pointed out in that there is a negative correlation between the fat amount and the motor fitness tests. This result contradicts the study of Al-Thaher (2013) who indicated that there is no relationship between the Endomorphic component, agility and coordination. It shares the study of Al-Salaimeh's (1994) results which said that the Mesomorphic component is directly related to excellence in agility, the more the muscular feature increases, the less the time needed to pass the agility test.

It is clear that there are no relationships or influences for somatotypes on the variables of static balance and coordination, whereas there were relations between the somatotypes and the variables of dynamic balance and agility. Regarding the variable of dynamic balance, the 2 somatotypes of Mesomorph and Ectomorph contributed effectively and statistically significant, where their total contribution percentage (R Square Change) reached (0.041), whereas the biggest contribution was for the Mesomorph component which was (0.102), and it is statistically significant because the corresponding level for its standard value was $(P=0.001)$, followed by the Ectomorph component with a contribution percentage that reached $(0.038)$, a statistically significant level because its corresponding value was $(P=0.032)$. 
While, Regarding the variable of agility, also, the 2 somatotypes of Mesomorph and Ectomorph contributed effectively and statistically significant, where their total contribution percentage (R Square Change) reached (0.092), whereas the biggest contribution was for the Mesomorph component which was (0.054), and it is statistically significant because the corresponding level for its standard value was $(P=0.003)$, followed by the Ectomorph component with a contribution percentage that reached (0.038), a statistically significant level because its corresponding value was $(P=0.036)$. This result differs from Al-Thaher's study $(2013)$ result which indicated that there are no relation between the Mesomorph component, agility and balance.

These findings are considered logical in light of the fact that the Mesomorphic component is the best somatotype in tests that require speed, followed by the Ectomorph somatotype because of their lack of obesity which is considered an obstacle that hinders the performance of movements quickly and with more agility. Also, tests which need speed, precision, balance and compatibility usually require the muscular strength and its aspects. That agrees with what Al-Salaimeh (1994) indicated in her study in that the more the fat increases, the more the speed time increases, and this is a negative influence.

\section{Conclusion}

Mesomorphic Endomorph was the prevailing somatotype for male students in general and for the students of 3rd and 4th academic years, whereas the balanced endomorphic was the prevailing one among the 1 st and 2 nd years.

Also, for female students, the balanced endomorphic was the prevailing somatotype in general and for the 3rd and 2nd academic years, whereas the Mesomorphic Endomorph was the prevailing one among the 1st and 4th years. Moreover, existence of differences in the somatotypes iterations among the male sample of students was represented by the prevalence of Mesomorphic Endomorph one and its difference from the other somatotypes which obtained the following order: Ectomorphic endomorph, Ectomorphic Mesomorph, Endomorphic Ectomorph. Whereas, the existence of differences in the somatotypes iterations among the female sample of students was represented by the prevalence of Mesomorphic Endomorph one and its difference from the other somatotypes which obtained the following order: Balanced Endomorph, Ectomorphic Endomorph, central. Furthermore, the Endomorph somatotype contributed effectively to the static balance and agility among the male sample students, whereas the Mesomorph and Ectomorph somatotypes contributed effectively to the dynamic balance and agility among the female sample students.

\section{Recommendations}

According to these conclusions the researcher recommended that:

The necessity of considering the somatotypes measurements when selecting students so that students who have the Mesomorphic or Ectomorphic somatotypes have to be chose. Also, using Heath \& Carter method for identifying somatotypes given its precision when selecting students. Furthermore, It is necessary to consider and benefit from this study findings through generalizing them to who are concerned so as to find out the mechanism and apply the necessary procedures to reduce the prevalence of the Endomorph type among students, as well as improving the Mesomorph feature through applying specific training programs. And considering the nature of these somatotypes contribution to the coordinating abilities through reinforcing the Mesomorph and Ectomorph components and reducing the increase of the Endomorph component. As well, conducting similar studies that address the relationship between somatotypes and other physical fitness components.

\section{References}

Allawi, T. ( 2005). Evaluation of Somatotype for a Number of Track and Field Events in Iraq. Journal of Research Basic Education, 2, 222-238.

Al-Salaimeh, K. (1994). Somatotype and Its Relation to Physical Fitness Level of Students of Faculty of Physical Education in the University of Jordan. MS Theses, Amman: University of Jordan.

Al-Thaher, S. (2013). Dominant Body Type and Its Ability to Contribute and Predict in Motor Fitness for Students of Teacher-Preparation Institute /Mosul. AL-RAFDEEN Journal of Sports Science, 19, 1-19.

Arak, M. (2008). Evaluation Some Physical, Skills and Physiological Indicators According to Physical Classifications of Soccer Players Aged (14-17 Years). Ph.D. Thesis, Babylon: University of Babylon.

Bilge, M., \& Tuncel, F. (2003). Investigation of Relationship between Handball Players' Anaerobic Power and Capacity. 
Journal of Physical Education and Sport, 8, 68.

Carter, J. (2002). The Heath-Carter Anthropometric Somatotype-Instruction Manual. Surrey TeP and ROSSCRAFT.

Claudio, S., Daniel, M., Eunice, O., Henrique, A., \& Rita, A. (2014). Body Shifter-Software to Determine and Optimize an Individual's Somatotype. Procedia Technology, 16, 1456-1461. http://dx.doi.org/10.1016/j.protcy.2014.10.165

Colakoglu, T., Er, F., Ipekoglu, G., Karacan, S., Colakoglu, F., \& Zorba, E. (2014). Evaluation of Physical, Physiological and Some Performance Parameters of the Turkish Elite Orienteer's, Procedia-Social and Behavioral. Sciences, 152, 403408. http://dx.doi.org/10.1016/j.sbspro.2014.09.220

Gualdi-Russo, E., \& Zaccagni, L . (2001). Somatotype, Role and Performance in Elite Volleyball Players. Journal of Sports Medicine and physical fitness, 41, 256-262.

Hassanein, M. (1995). Somatotypes for Male and Female Sports Champions. Cairo: Dar Al Fiker Al Arabi.

Hassanein, M. (2003). Measurement and Evaluation in Physical Education and Sports (5th ed.). Cairo: Dar Al Fiker Al Arabi.

Hussein, U. (2004). Somatotypes and Their Effect on Knee Joints Ligaments Injuries of the College of Physical Education Students. Journal of Physical Education, 13, 65-76.

Ibrahim, W., Hussein, H., \& Abdul Amir, R. (2012). The Relationship between Somatotypes and the Performance of Some Ground Movements among Students in the Faculty of Physical Education. Journal of Sports Education, 4, 45-59.

Liiv, H., Wyon, M., Jurimae, T., Purge, P., Saar, M., Maestu, J., \& Jurimae, J. (2013). Anthropometry and Somatotypes of Competitive Dance Sport Participants: A Comparison of Three Different Styles. HOMO_Journal of Comparative Human Biology, 65, 155-160.

Lundy, B., O'Connor, H., Fiona, P., \& Caterson, I. (2006). Anthropometric Characteristics and Competition Dietary Intakes of Professional Rugby League Players. International Journal of Sport Nutrition and Exercise Metabolism, 16, $199-213$.

Muhammed, S., Nasir, A., Yousef, H., \& Muhammed, R. (2009). The Role and Importance of Identifying Smatotypes in Evaluation Secondary School Curricula in Algeria. Journal of Sports Sciences, No. 1, 145-158.

Sogut, M., Muniroglu, S., \& Deliceoglu, G. (2004). Investigation of the Young and Male Tennis Players' Anthropometric and Somatotype Characteristics in Different Categories. Spormetre Journal of Physical Education and Sport Sciences, No. $4,156$.

Tahillioglu, A., Sevim, Y., Pulur, A., \& Alpkaya, U. (2000). Determination of Anthropometric and Somatotype Components at Swimmers. Gazi: Physical Education and Sport Sciences Congress Book.

Van Someren, K., \& Palmer, G. (2003). Predictor of 200m Sprint Kayaking Performance. Applied Journal of Physiology, Nutrition and Metabolism, 28, 505-517.

Vedat, A. (2013). Somatotypes of Male Whitewater Canoe Athletes of the Turkish National Canoe Team. African Journal of Agricultural Education, 1, 051-055. 